\title{
Adenoma Recurrence after Endoscopic Piecemeal Mucosal Resection of Colorectal Flat Lesions: Applicability of the Sydney EMR Recurrence Tool in a Non-Tertiary Centre
}

\author{
Maria Azevedo Silva Carina Leal André Ruge Alexandra Fernandes \\ Liliana Eliseu Helena Vasconcelos
}

Department of Gastroenterology, Centro Hospitalar de Leiria, Leiria, Portugal

\section{Keywords}

Adenoma recurrence - Endoscopic piecemeal mucosal resection $\cdot$ Colorectal flat lesions

\section{Abstract}

Introduction: Endoscopic mucosal resection (EMR) is the treatment of choice for non-invasive colorectal flat lesions. When endoscopic piecemeal mucosal resection (EPMR) is performed, endoscopic surveillance is necessary due to the risk of recurrence. The Sydney EMR Recurrence Tool (SERT) is a 0-4 scale that classifies lesions according to size, occurrence of intraprocedural bleeding (IPB) and presence of high-grade dysplasia (HGD). Our goal is to evaluate the applicability of SERT in predicting adenoma recurrence (AR) after EPMR. Methods: This is a retrospective single-centre study with inclusion of lateral spreading lesions $\geq 20 \mathrm{~mm}$, consecutively resected by EPMR from March 2010 to February 2018, with at least 1 endoscopic re-evaluation. Results: A total of 181 lesions were included, corresponding to 174 patients with a mean age of 68 years and male gender predominance $(61 \% ; n=106)$. The most frequent location was the ascending colon (34\%; $n=62$ ). Lesions were assessed according to Paris Classification (PC): 0-Ila: 39\% ( $n=71)$; 0-Ilb:
$24 \%(n=43) ; 0-I l a+$ Is: $23 \%(n=42) ; 0-I l a+I l b: 6 \%(n=11)$; 0 -Ila + Ilc: $2 \%(n=3)$. The mean size of the lesions was $33 \pm$ $11 \mathrm{~mm}$, with 25 (14\%) being $\geq 40 \mathrm{~mm}$. IPB occurred in 9 cases (5\%), and 44 lesions (24\%) displayed HGD. Sixty-six lesions (36.5\%) were classified as SMSA (size, morphology, site, and access score) level 4. Adjunctive therapy with argon plasma coagulation (APC) was used in $37 \%(n=67)$ of cases. The 6-month AR rate was $16 \%(n=29)$. According to SERT groups, the AR rate was: SERT 0: $12 \%(14 / 120)$; SERT 1: 17\% (6/35); SERT 2: $25 \%$ (3/12); SERT 3: 30\% (3/10); SERT 4: 75\% (3/4). Two of the three SERT variables (size $\geq 40 \mathrm{~mm}$ and IPB) were associated with recurrence at 6 months $(p<0.05)$. HGD and the remaining tested variables (age, gender, localization, accessibility, PC, use of APC/biopsy forceps and occurrence of delayed bleeding) were not associated with AR. SERT 0 lesions showed an inferior risk of 6-month AR (adjusted OR = 2.62; $p=0.035$ ), with a negative predictive value of $88 \%$. SMSA correlated with SERT $(p<0.001)$ and SMSA level 4 was associated with 6-month $\operatorname{AR}(p=0.007)$. Lesions classified both as SERT 0 and SMSA level $<4$ had the lowest 6-month recurrence rate $(9.2 \%)$. The 24 -month recurrence rate was $23 \%$ $(n=41)$. When applying the Kaplan-Meier method, cumulative recurrence was significantly lower in SERT 0 lesions ( $p=$ 0.006, log-rank test). Discussion/Conclusion: Resection of karger@karger.com www.karger.com/pjg

Karger $\stackrel{\text { ' }}{5}$

GOPEN ACCESS (c) 2021 Sociedade Portuguesa de Gastrenterologia. Published by S. Karger AG, Basel

This article is licensed under the Creative Commons AttributionNonCommercial-NoDerivatives 4.0 International License (CC BY NC-ND) (http://www.karger.com/Services/OpenAccessLicense). Usage and distribution for commercial purposes as well as any distribution of modified material requires written permission.
Correspondence to:

Maria Azevedo Silva, maria.aams@gmail.com 
flat colorectal lesions by EPMR has a considerable risk of recurrence, mostly in SERT 1-4 lesions. SERT 0 lesions, especially with SMSA level $<4$, show a lower risk of recurrent adenoma, which might allow longer intervals to first endoscopic surveillance in the future.

(c) 2021 Sociedade Portuguesa de Gastrenterologia Published by S. Karger AG, Basel

\section{Adenoma recorrente após mucosectomia fragmentada de lesões colorrectais planas: aplicabilidade do SERT num centro não terciário}

\section{Palavras Chave}

Adenoma recorrente - Mucosectomia fragmentada .

Lesões colorrectais planas

\section{Resumo}

Introdução: A mucosectomia endoscópica é a terapêutica de eleição nas lesões colorretais planas não invasivas e, quando fragmentada, obriga a vigilância endoscópica, dado o risco de recorrência. O Sydney Endoscopic Mucosal Resection Recurrence Tool (SERT) é uma escala de 0 a 4 que classifica as lesões em função da dimensão, ocorrência de hemorragia imediata na sua excisão (HI) e presença de displasia de alto grau (DAG). Pretende-se avaliar a aplicabilidade do SERT na predição de adenoma recorrente (AR) após mucosectomia fragmentada. Métodos: Estudo retrospetivo unicêntrico com inclusão de todas as lesões planas $\geq 20 \mathrm{~mm}$ excisadas por mucosectomia fragmentada, entre Março/2010 e Fevereiro/2018, com pelo menos uma vigilância endoscópica. Resultados: Incluídas 181 lesões, correspondentes a 174 doentes com idade média de 68 anos e predomínio do sexo masculino $(61 \% ; n=106)$. A localização mais frequente foi o cólon ascendente (34\%; $n=62)$. As lesões foram avaliadas segundo a classificação de Paris (CP): 0-Ila: 39\% ( $n=71)$; 0-Ilb: 24\% ( $n=43) ; 0-\| l a+$ Is: $23 \%(n=42) ; 0-I l a+$ Ilb: $6 \%(n=11) ; 0-I l a+$ Ilc: $2 \%(n=$ 3). O tamanho médio foi $33 \pm 11 \mathrm{~mm}$, tendo 25 (14\%) dimensões $\geq 40 \mathrm{~mm}$. Verificou-se HI em 9 casos (5\%) e DAG em 44 (24\%). O nível SMSA (size, morphology, site, and access score) foi 4 em 66 lesões (36.5\%). Realizou-se terapêutica com árgon plasma (APC) em $37 \%(n=67)$ dos casos. A taxa de AR aos 6 meses foi: SERT 0: 12\% (14/120); SERT 1: $17 \%$ (6/35); SERT 2: $25 \%$ (3/12); SERT 3: 30\% (3/10); SERT 4: 75\% (3/4); global: 16\% (29/181). O AR aos 6 meses associou-se à dimensão $\geq 40 \mathrm{~mm}$ e à $\mathrm{HI}(p<0.05)$. A DAG não mostrou relação com a recorrência, assim como a idade, sexo, localização, acessibilidade, $C P$, terapêutica adju- vante (APC/pinça de biópsias) e ocorrência de hemorragia tardia. As lesões SERT 0 apresentaram menor risco de AR aos 6 meses (OR ajustado $=2.62 ; p=0.035$ ), com um valor preditivo negativo de $88 \%$. O SMSA correlacionou-se com o SERT ( $p<0.001)$, estando o nível SMSA 4 associado à recorrência aos 6 meses $(p=0.007)$. As lesões classificadas como SERT 0 e nível SMSA $<4$ apresentaram a menor taxa de AR (9.2\%). A taxa de recorrência aos 24 meses foi $23 \%$ $(n=41)$. Aplicando o método de Kaplan Meier, a recorrência cumulativa foi menor nas lesões SERT 0 ( $p=0.006$, teste log-rank). Discussão/Conclusão: A excisão de lesões planas por mucosectomia fragmentada apresenta uma taxa de recorrência considerável, sobretudo em lesões SERT 1-4. As lesões SERT 0, particularmente se nível SMSA $<4$, apresentam menor risco de recidiva, o que poderá possibilitar um prolongamento do intervalo até à primeira vigilância endoscópica.

(C) 2021 Sociedade Portuguesa de Gastrenterologia Publicado por S. Karger AG, Basel

\section{Introduction}

Endoscopic mucosal resection (EMR) is the treatment of choice for non-invasive colorectal flat lesions [1]. When en bloc resection is not possible, endoscopic piecemeal mucosal resection (EPMR) may be considered.

Despite its advantages over surgery and submucosal dissection for non-invasive lesion treatment, in both cost and safety [2-4], EMR has a substantial risk of recurrence, particularly when piecemeal resection is performed $[5,6]$. A meta-analysis of 33 studies found a recurrent adenoma rate of 20\% after EPMR of non-pedunculated colorectal lesions [5]. Therefore, after piecemeal resection, endoscopic surveillance remains a necessity.

Some endoscopic features and procedural variables have been linked to greater risk of recurrent adenoma. Several studies demonstrated the association between large lesion size and adenoma recurrence [6-9]. Additionally, localization in the right colon, namely involving the ileocecal valve or the appendix orifice, and intraprocedural bleeding (IPB) were also associated with recurrent lesions $[6,7]$. A previously validated score that defines polyp complexity according to size, morphology, site and access (SMSA score) has been shown to be useful in predicting adenoma recurrence in more complex lesions (i.e., SMSA level 4) $[10,11]$.

Current guidelines recommend an endoscopic followup within 6 months after piecemeal resection of polyps $\geq 20 \mathrm{~mm}$ [12]. Because recurrent lesions frequently do not 
have advanced histological features and are endoscopically treatable $[7,13,14]$, endoscopic surveillance within 6 months for all EPMR has been questioned. A prospective multicenter study by Tate et al. [8] created and validated a tool which aims to predict the risk of recurrent adenoma after EPMR of colorectal lateral spreading lesions: the Sydney EMR Recurrence Tool (SERT), a 0-4 scale that classifies lesions according to size (2 points if $\geq 40 \mathrm{~mm}$ ), occurrence of IPB (1 point) and presence of high-grade dysplasia (HGD; 1 point). SERT 0 lesions presented a considerably lower risk of recurrence and could safely undergo first endoscopic surveillance at 18 months, according to the authors.

Our goal is to evaluate the applicability of SERT in predicting adenomatous recurrence after EPMR in a secondary centre cohort.

\section{Materials and Methods}

\section{Study Design}

A retrospective single centre study was conducted, including consecutive colorectal flat lesions referred for EMR, from March 2010 to February 2018. Lateral spreading lesions with a size of 20 $\mathrm{mm}$ or greater, with or without a sessile component, were included if a complete resection was achieved by piecemeal mucosectomy. Exclusion criteria included en bloc resection, previous attempt of resection, evidence of malignancy in the histopathologic analysis and absence of at least 1 endoscopic surveillance.

All patients provided written informed consent for colonoscopy. The study was conducted according to the Declaration of Helsinki and approved by the ethical board of Centro Hospitalar de Leiria, Portugal.

\section{Procedures and Equipment}

All colonoscopies were performed with high-definition scopes (Olympus ${ }^{\circledR}$ GIF-H180 or GIF-H185, depending on the colonoscope availability) and with EVIS EXERA III CV-190 Olympus video processors, using room air insufflation. Lesions were resected by EPMR, using oval and/or hexagonal hot polypectomy snares, with fractionated current (Endocut mode Q, effect 3, ERBE VIO 300 S), after submucosal injection of a solution of saline, methylene blue and diluted adrenaline $(1: 100,000)$. If residual lesion was suspected at the time of resection, adjunctive endoscopic techniques, including thermal ablation of lateral margins of the mucosectomy site with argon plasma coagulation (APC) and/or cold biopsy forceps excision completion, were used according to the endoscopist's preferences. Narrow-band imaging (NBI) was used as an adjuvant to white light to evaluate recurrent lesions/scars according to the endoscopist's preference and expertise.

\section{Data Collection and Outcome Definition}

Data were collected by consultation of patients' clinical, endoscopic and histopathologic records, including age, gender, size of the lesions, morphology, location, access, adjuvant endoscopic techniques, occurrence of bleeding, anatomopathological charac- terization and endoscopic follow-up. SERT was calculated and each lesion was assigned to the SERT 0 or the SERT 1-4 group. Each lesion was also classified as SMSA level 3 or 4 according to SMSA score.

The primary endpoint was to evaluate the utility of SERT in the prediction of the 6-month adenoma recurrence rate, which was defined by the presence of dysplasia in the anatomopathological evaluation of the recurrent resected tissue. Endoscopic image enhancement techniques like NBI were not used to define recurrent adenoma. Secondary endpoints included the applicability of SERT in other time points, the correlation between SERT and SMSA score and the evaluation of the association between other endoscopic factors and recurrent adenoma.

\section{Statistical Analysis}

Statistical analysis was conducted in Statistical Package for the Social Sciences (SPSS), version 23.0 (IBM, Armonk, NY, USA). Mean and standard deviation were used to describe normally distributed variables, while median and interquartile range (IQR) were used to describe skewed distributed variables. Bivariate analysis was performed using Student $t$ test for normally distributed variables, Mann-Whitney U test and Spearman's correlation coefficient for skewed distribute variables and $\chi^{2}$ test for dichotomous variables. A bivariate logistic regression was conducted for the primary endpoint, considering the following potential confounding variables: age, gender, lesion location (right colon vs. left colon/ rectum), lesion accessibility (easy vs. difficult access), use of adjunctive therapy (APC/biopsy forceps) and occurrence of delayed bleeding, defined as haemorrhage after the end of the procedure requiring endoscopic treatment. The Kaplan-Meier method was applied to evaluate time to recurrence in each group of lesions according to SERT classification. A $p$ value $<0.05$ was regarded as statistically significant.

\section{Results}

\section{Study Population}

Six hundred and two colorectal flat lesions were considered for inclusion (Fig. 1). Two hundred and eightythree lesions were excluded for having a dimension inferior to $20 \mathrm{~mm}$ and 26 were resected en bloc. In 48 cases, resection was not complete; 24 lesions were not considered resectable by EMR; 3 lesions were excluded due to previous attempts of resection. Five lesions revealed histopathologic features compatible with adenocarcinoma and were thus excluded from the analysis. Additionally, 32 patients were lost to follow-up before endoscopic reevaluation could be performed and/or had insufficient data in clinical records. Therefore, 181 lesions were included in the analysis, corresponding to 174 patients, with a mean age of $67.8 \pm 9.6$ years and a predominance of male gender $(60.9 \% ; n=106)$. 


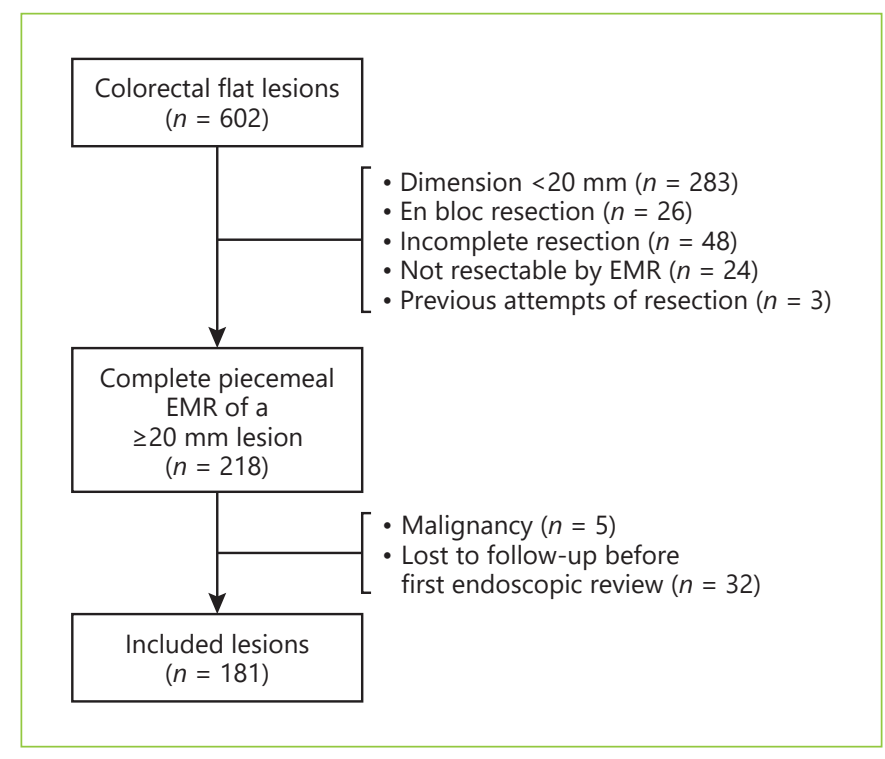

Fig. 1. Study population flowchart. EMR, endoscopic mucosal resection.

\section{Lesion Characteristics and Procedural Variables}

Endoscopic and histopathological features of the included lesions are presented in Table 1. The mean size of the lesions was $33.4 \pm 11.5 \mathrm{~mm}$. Morphology was described using the Paris Classification. Most of the lesions were elevated, with or without a sessile component (0-IIa: $39.2 \%$ [ $n=71] ; 0$-IIa + Is: $23.2 \%$ [ $n=42])$. The majority of the lesions were located in the right colon $(64.1 \% ; n=$ $116)$, mostly in the ascending colon $(34.3 \% ; n=62)$, follow by the rectum $(19.9 \% ; n=36)$. Access to the lesion was considered difficult in $6.1 \%(n=11)$ of cases.

Adjunctive endoscopic therapy was used in $45.3 \%$ ( $n$ $=82$ ) of cases, namely thermal ablation of lateral margins of the mucosectomy site with APC $(37.0 \% ; n=67)$ and excision complementation with biopsy forceps $(8.3 \%$; $n=$ $15)$. IPB occurred in $5.0 \%(n=9)$ of cases and delayed bleeding was verified in $7.2 \%(n=13)$. There was 1 case of colonic perforation, treated with clip closure and antibiotic therapy. All complications were successfully managed with endoscopic treatment. Most lesions were tubulovillous adenomas $(70.8 \% ; n=128)$, followed by tubular adenomas $(19.9 \% ; n=36)$. HGD was documented in $24.3 \%(n=44)$ of cases.

The majority of lesions was classified as SERT $0(66.3 \%$; $n=120)$, followed by SERT $1(19.3 \% ; n=35)$, SERT 2 $(6.6 \% ; n=12)$, SERT $3(5.5 \% ; n=10)$ and finally SERT 4 $(2.2 \% ; n=4)$. Sixty-six lesions $(36.5 \%)$ were classified as SMSA level 4, and the remaining were SMSA level 3.
Table 1. Baseline characteristics of the lesions submitted to piecemeal endoscopic mucosal resection, procedural variables and SERT points

\begin{tabular}{|c|c|}
\hline Lesion Characteristics & $(n=181)$ \\
\hline Size, $m m$ (mean \pm standard deviation) & $33.4 \pm 11.5$ \\
\hline \multicolumn{2}{|l|}{ Localization, $n(\%)$} \\
\hline Cecum & $22(12.2)$ \\
\hline Ascending colon & $62(34.3)$ \\
\hline Ileocecal valve involvement & $5(2.8)$ \\
\hline Hepatic flexure & $13(7.2)$ \\
\hline Transverse colon & $19(10.5)$ \\
\hline Splenic flexure & $3(1.7)$ \\
\hline Descendent colon & $9(5.0)$ \\
\hline Sigmoid colon & $17(9.4)$ \\
\hline Rectum & $36(19.9)$ \\
\hline Difficult access, $n(\%)$ & $11(6.1)$ \\
\hline SMSA points (mean \pm standard deviation) & $12.0 \pm 1.5$ \\
\hline SMSA level $4, n(\%)$ & $66(36.5)$ \\
\hline \multicolumn{2}{|l|}{ Paris Classification, $n(\%)$} \\
\hline 0 -IIa & $71(39.2)$ \\
\hline $0-\mathrm{IIb}$ & $43(23.8)$ \\
\hline 0 -IIa + Is & $42(23.2)$ \\
\hline 0-IIa + IIb & $11(6.1)$ \\
\hline 0 -IIa + IIc & $3(1.7)$ \\
\hline 0 -IIa + IIb + Is & $1(0.6)$ \\
\hline \multicolumn{2}{|l|}{ Histopathology, $n(\%)$} \\
\hline Tubulovillous adenoma & $128(70.8)$ \\
\hline Tubular adenoma & $36(19.9)$ \\
\hline Hyperplasic/serrated polyp & $14(7.7)$ \\
\hline Serrated adenoma & $2(1.1)$ \\
\hline Villous adenoma & $1(0.6)$ \\
\hline High-grade dysplasia, $n(\%)$ & $44(24.3)$ \\
\hline \multicolumn{2}{|l|}{ Procedural Variables } \\
\hline \multicolumn{2}{|l|}{ Lateral margins ablation with argon plasma } \\
\hline $\begin{array}{l}\text { Excision complementation with biopsy forceps, } \\
n(\%)\end{array}$ & $15(8.3)$ \\
\hline Intraprocedural bleeding, $n(\%)$ & $9(5.0)$ \\
\hline Delayed bleeding, $n(\%)$ & $13(7.2)$ \\
\hline Colon perforation, $n(\%)$ & $1(0.6)$ \\
\hline \multicolumn{2}{|l|}{ SERT points, $n(\%)$} \\
\hline 0 & $120(66.3)$ \\
\hline 1 & $35(19.3)$ \\
\hline 2 & $12(6.6)$ \\
\hline 3 & $10(5.5)$ \\
\hline 4 & $4(2.2)$ \\
\hline
\end{tabular}

SMSA, size, morphology, site, access score; SERT, Sydney Endoscopic Mucosal Resection Recurrence Tool.

\section{Endoscopic Surveillance and Residual Lesion \\ Resection}

The median time to first endoscopic surveillance was 6 months (IQR: 4-7 months). Visible recurrent lesions were seen in $28.2 \%$ of cases $(n=51)$, with a dimension $>10 \mathrm{~mm}$ 
Fig. 2. Endoscopic appearance of recurrent adenoma before (left) and after (right) endoscopic treatment.

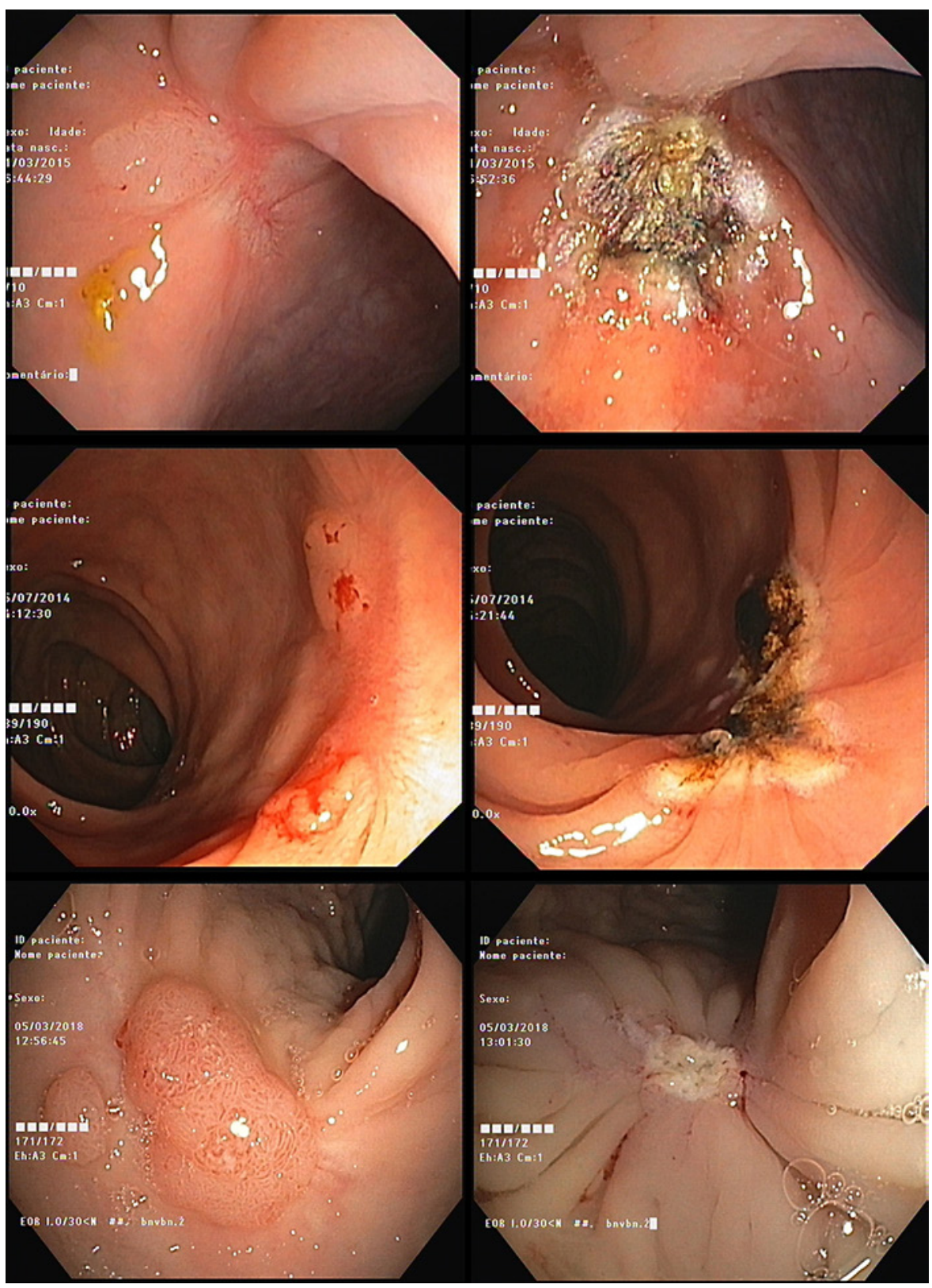

in $4.4 \%(n=7)$. Regular scars were observed in $45.9 \%$ $(n=83)$ of first endoscopic re-evaluations. No scar nor apparent residual lesion was seen in $26.0 \%$ of cases $(n=47)$.

Visible residual lesions were preferably resected by en bloc polypectomy snare resection $(36 \% ; n=18)$. When that could not be achieved, excision was carried out through EPMR $(6 \% ; n=3)$ and/or completed with biopsy forceps $(64 \% ; n=32)$. After resection of the residual tissue, adjunctive ablation of the scar with APC was performed in 13 cases (26\%; Fig. 2). All resected tissue was sent to anatomopathological evaluation: 27 lesions
(52.9\%) corresponded to recurrent adenoma and 24 (47.1\%) were hyperplastic tissue (Fig. 3). Nineteen percent $(16 / 83)$ of regular scars were biopsied according to the endoscopist's decision. The median endoscopic follow-up time was 11 months (IQR: 6-20 months).

\section{Recurrent Adenomatous Lesions}

The 6-month adenoma recurrence rate was $16.0 \%$ $(n=29)$. In the vast majority of cases, recurrent adenoma corresponded to visible residual lesions in endoscopic surveillance $(93.1 \% ; n=27 / 29)$. However, 2 of the regular 
Fig. 3. Visible recurrent lesions with (left) and without (right) adenoma recurrence.

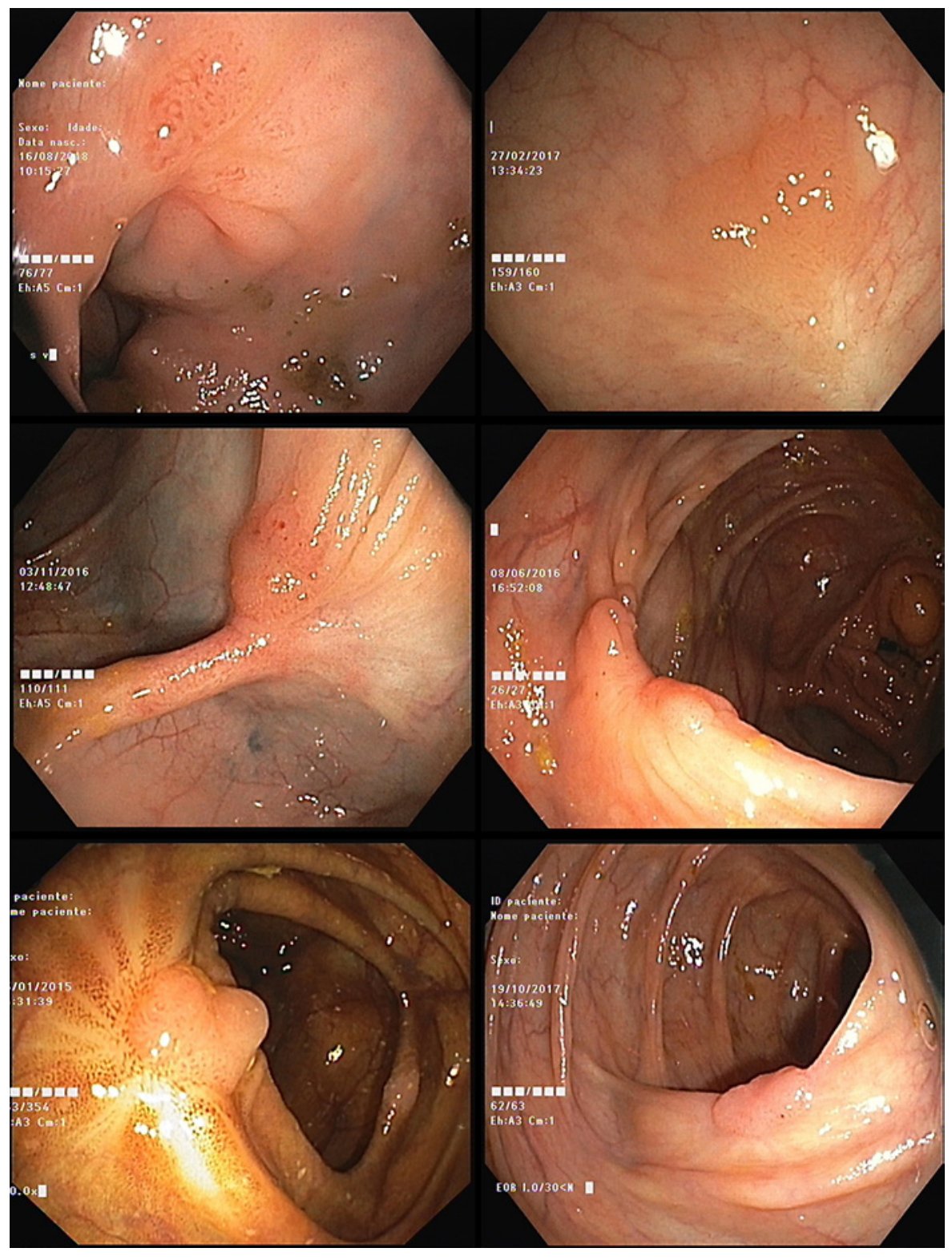

scars' biopsies revealed adenomatous transformation with low-grade dysplasia.

Six-month recurrent adenoma occurred in $11.7 \%$ $(14 / 120)$ of SERT 0 lesions, $17.1 \%(6 / 35)$ of SERT 1 lesions, $25.0 \%(3 / 12)$ of SERT 2 lesions, 30.0\% (3/10) of SERT 3 lesions and $75.0 \%(3 / 4)$ of SERT 4 lesions. Two of the three SERT variables (size $\geq 40 \mathrm{~mm}$ and IPB) were associated with recurrence at 6 months $(p=0.003$ and $p=$ 0.017 , respectively; Table 2). HGD was not associated with recurrent adenoma. Lesions without any of the SERT variables (SERT 0) showed an inferior risk of recurrence $(p=0.016)$, corresponding to a negative predictive value of $88.3 \%(n=106 / 120)$ for recurrent adenoma at 6 months.
None of the other tested variables (age, gender, localization of the lesion, morphology according to Paris Classification, lesion accessibility, use of adjunctive therapy with APC/biopsy forceps and occurrence of delayed bleeding) showed an association with 6-month recurrence. Nevertheless, the number of SMSA score points correlated with SERT $(p<0.001)$, and SMSA level 4 was associated with 6-month adenoma recurrence as well $(25.8 \%$ [ $n=17 / 66]$ in SMSA level 4 vs. $10.4 \%$ [ $n=12 / 115]$ in SMSA level 3; $p=0.007$ ).

A bivariate logistic regression was conducted to control for potential confounding variables. When adjusted for age, gender, lesion localization, accessibility, endo- 
Table 2. Analysis of recurrent adenoma after 6 months according to SERT and its components

\begin{tabular}{|c|c|c|c|c|c|c|c|c|}
\hline & $\begin{array}{l}\text { Overall } \\
(n=181)\end{array}$ & $\begin{array}{l}6 \text {-month recur- } \\
\text { rent adenoma } \\
(n=29)\end{array}$ & \multicolumn{3}{|c|}{ Univariate analysis } & \multicolumn{3}{|c|}{ Multivariate analysis } \\
\hline Intraprocedural bleeding & $9(5.0)$ & $4(44.4)$ & 4.70 & $1.18-18.73$ & 0.017 & 4.73 & $1.14-19.56$ & 0.032 \\
\hline High-grade dysplasia & $44(24.3)$ & $10(22.7)$ & 1.83 & $0.78-4.30$ & 0.163 & 1.73 & $0.69-4.38$ & 0.246 \\
\hline SERT $1-4$ & $61(33.7)$ & $15(24.6)$ & 2.47 & $1.10-5.53$ & 0.025 & 2.62 & $1.07-6.41$ & 0.035 \\
\hline
\end{tabular}

Values are $n(\%)$. Bold values correspond to $p$ values $<0.05$. SERT, Sydney Endoscopic Mucosal Resection Recurrence Tool; OR, odds ratio; CI, confidence interval. ${ }^{1}$ Adjusted OR for age, gender, lesion localization (right colon vs. left colon/rectum), lesion accessibility (easy vs. difficult access), use of adjunctive therapy (argon plasma coagulation/biopsy forceps) and occurrence of delayed bleeding.

Fig. 4. Kaplan-Meier estimates of the cumulative adenoma recurrence after piecemeal endoscopic mucosal resection according to SERT groups.

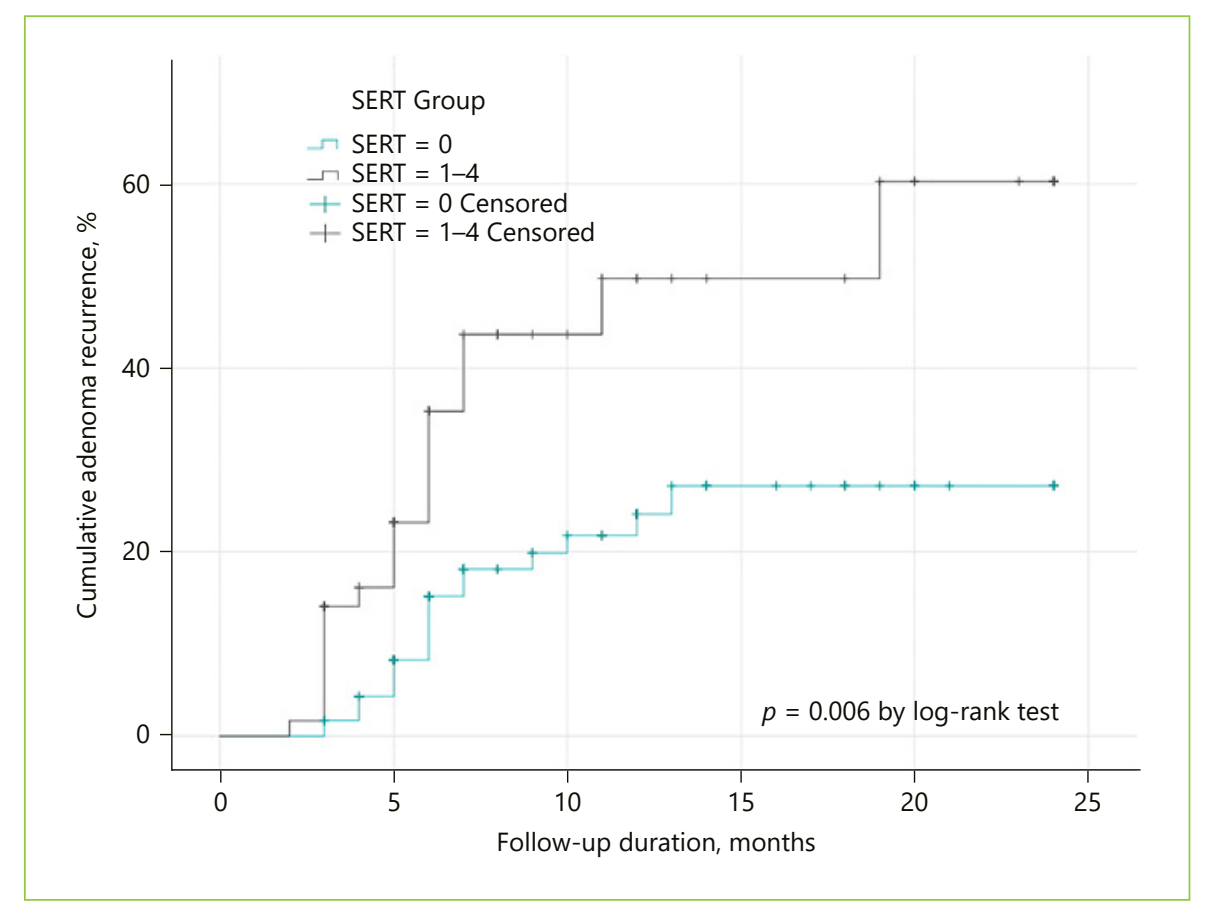

scopic adjunctive therapy and occurrence of delayed bleeding, the association between SERT and 6-month recurrence remained statistically significant $(p=0.035)$, with an adjusted odds ratio of 2.62 for SERT 1-4 lesions (Table 2). Additionally, SERT and SMSA score were merged in the same bivariate analysis. Lesions with both high-risk features (i.e., SERT 1-4 and SMSA level 4) presented a $33.3 \%(n=11 / 33)$ risk of 6 -month recurrence $(p=0.003)$, whereas SERT 0 lesions with SMSA level 3 showed a $9.2 \%(n=8 / 87)$ recurrence rate at 6 months.

The 24 -month recurrence rate was $22.7 \%(n=41)$. At this time point, SERT 0 lesions maintained their inverse association with recurrent adenoma $(p=0.020)$, with a recurrence rate of $17.5 \%(n=21 / 120)$ versus $32.8 \%$ ( $n=$ $20 / 61$ ) in SERT 1-4 lesions. SMSA level 4 was also associated with 24-month recurrence, with a recurrence proportion of $33.3 \%(n=22 / 66)$ versus $16.5 \%(n=19 / 115)$ in SMSA level $3(p=0.009)$. Rectal lesions presented a higher rate of recurrent adenoma at this time point $(36.1 \%$ $[n=13 / 36], p=0.031)$. However, this difference decreases if only SERT 0 lesions are considered.

The Kaplan-Meier method was used to generate the cumulative incidence of recurrent adenoma (Fig. 4). The cumulative adenoma recurrence rate was higher in SERT 
1-4 lesions than in SERT 0 lesions. According to the logrank test, this difference was statistically significant $(p=$ 0.006).

Among patients who did not present adenoma recurrence in the 2-year period after EPMR, we were able to follow up 15 patients for 3 or more years. Very late recurrence (more than 3 years after EPMR) was detected in 2 of these patients: one at 3 years and 3 months and the other 5 years after EPMR, both corresponding to initial SERT 1 lesions due to HGD. Both recurrent adenomas displayed low-grade dysplasia. Since no regular scars were biopsied during endoscopic surveillances 3 or more years after EPMR, very late recurrence was only detected in the presence of endoscopic visible recurrent lesions, either with white light or NBI. In the SERT 0 group, the last recurrent adenoma was detected 18 months after EPMR.

All recurrent lesions were resected endoscopically, with the exception of 1 SERT 4 lesion that recurred as a HGD adenoma in 2 consecutive endoscopic re-evaluations. The patient was submitted to right hemicolectomy. In the SERT 0 group, all recurrent adenomas displayed low-grade dysplasia.

\section{Discussion/Conclusion}

To the best of our knowledge, this is the first non-tertiary centre study to contemplate the applicability of SERT in adenoma recurrence after EPMR of colorectal lesions. Our results suggest that SERT is useful in predicting adenoma recurrence after EPMR at 6 months and cumulatively during 24 months of follow-up. Two of the three SERT variables (size $\geq 40 \mathrm{~mm}$ and IPB) were independently associated with recurrence, which is in line with previous research [8] and may be explained by a greater complexity of mucosectomy in larger bleeding lesions. However, we could not demonstrate an association between HGD and adenoma recurrence at 6 months. Previous research also failed to demonstrate this association $[6,9]$. Arguably, a higher number of patients would be necessary to evaluate the association of HGD with 6-month adenoma recurrence, as was performed by Tate et al. [8]. On the other hand, in our cohort, all recurrent adenomas diagnosed more than 18 months after EPMR corresponded to initial lesions with HGD (and were thus classified as SERT 1-4 lesions), suggesting that HGD may predict late recurrence and that SERT 0 lesions might not need long-term follow-up.
Our findings corroborate two recently published studies $[15,16]$, which showed similar results in tertiary centres, namely regarding adenoma recurrence rates at 6 months (14\% recurrence for flat lesions found by Alexandrino et al. [16] and $20 \%$ by Silva et al. [15]). The 6-month adenoma recurrence rates were $11.7 \%$ for SERT 0 lesions and $25.0 \%$ for SERT 1-4 lesions, which is similar to the rates observed in the study by Tate et al. [8] (10.3 and $27.8 \%$, respectively). For SMSA level 4, we found a recurrence rate of $25.8 \%$, while Alexandrino et al. [16] reported 21.7\%.

SERT was correlated with SMSA score and both scores could predict absence of recurrence. Lesions with both low-risk features (i.e., SERT 0 and SMSA level <4) presented the lowest risk of recurrence, with a $90.8 \%$ negative predictive value for recurrent adenoma at 6 months. In this group of lesions, all recurrent adenomas displayed low-grade dysplasia and were resected endoscopically. Our results support the suggestion of Tate et al. [8] that the interval to first endoscopic surveillance could be extended in SERT 0 lesions, especially if these lesions also meet the SMSA level $<4$ criteria.

We found a considerable difference between adenoma recurrence (16.0\%) and visible recurrent lesions (28.2\%). As seen in Figure 3, endoscopic white light evaluation of residual tissue does not allow the distinction between hyperplastic and adenomatous tissue. This discrepancy has been previously reported [8]. Earlier research has revealed that the absence of visible recurrent lesions has a high negative predictive value for adenoma recurrence, whereas the presence of visible residual tissue has a lower positive predictive value for histologic recurrence [17]. Despite these findings, we detected two recurrent adenomas in endoscopically normal appearing scars. Since the majority of mucosectomy scars was not biopsied when recurrent lesion was not suspected, this number might be underestimated. The fact that NBI was not routinely used to evaluate mucosectomy scars may have contributed to this underestimation.

Our study has some other limitations inherent to a retrospective single-centre study. We excluded 32 patients due to loss of follow-up and/or insufficient data in clinical records. EPMR and surveillance colonoscopies were performed by multiple endoscopists with different experiences in EMR and training in advanced endoscopic imaging. The sample size of our study might have been insufficient to draw some conclusions, namely to associate HGD with adenoma recurrence.

In conclusion, EPMR of large flat colorectal lesions has an important risk of recurrent adenoma, mostly in SERT 1-4 lesions. SERT 0 lesions show a significantly lower rate 
of recurrence. These findings may allow an extension in the interval to first endoscopic surveillance, if supported by future prospective data.

\section{Statement of Ethics}

The authors have no ethical conflicts to disclose.

\section{Conflict of Interest Statement}

The authors have no conflicts of interest to declare.

\section{Funding Sources}

There were no funding sources.

\section{Author Contributions}

M.A. Silva performed research, collected and analysed data and wrote the paper. C. Leal and A. Ruge collected data. A. Fernandes performed research, designed the study and revised the paper. L. Eliseu designed the study and revised the paper. H. Vasconcelos revised and approved the final manuscript.

\section{References}

1 Ferlitsch M, Moss A, Hassan C, Bhandari P, Dumonceau JM, Paspatis G, et al. Colorectal polypectomy and endoscopic mucosal resection (EMR): European Society of Gastrointestinal Endoscopy (ESGE) Clinical Guideline. Endoscopy. 2017 Mar;49(3):270-97.

2 Jayanna M, Burgess NG, Singh R, Hourigan LF, Brown GJ, Zanati SA, et al. Cost Analysis of Endoscopic Mucosal Resection vs Surgery for Large Laterally Spreading Colorectal Lesions. Clin Gastroenterol Hepatol. 2016 Feb;14(2):271-8.e1.

3 De Ceglie A, Hassan C, Mangiavillano B, Matsuda T, Saito Y, Ridola L, et al. Endoscopic mucosal resection and endoscopic submucosal dissection for colorectal lesions: A systematic review. Crit Rev Oncol Hematol. 2016 Aug;104:138-55.

4 Ahlenstiel G, Hourigan LF, Brown G, Zanati S, Williams SJ, Singh R, et al.; Australian Colonic Endoscopic Mucosal Resection (ACE) Study Group. Actual endoscopic versus predicted surgical mortality for treatment of advanced mucosal neoplasia of the colon. Gastrointest Endosc. 2014 Oct;80(4):668-76.

5 Belderbos TD, Leenders M, Moons LM, Siersema PD. Local recurrence after endoscopic mucosal resection of nonpedunculated colorectal lesions: systematic review and meta-analysis. Endoscopy. 2014 May;46(5):388402.

6 Briedigkeit A, Sultanie O, Sido B, Dumoulin FL. Endoscopic mucosal resection of colorectal adenomas $>20 \mathrm{~mm}$ : risk factors for recurrence. World J Gastrointest Endosc. 2016 Mar;8(5):276-81.
7 Moss A, Williams SJ, Hourigan LF, Brown G, Tam W, Singh R, et al. Long-term adenoma recurrence following wide-field endoscopic mucosal resection (WF-EMR) for advanced colonic mucosal neoplasia is infrequent: results and risk factors in 1000 cases from the Australian Colonic EMR (ACE) study. Gut. 2015 Jan;64(1):57-65.

8 Tate DJ, Desomer L, Klein A, Brown G, Hourigan LF, Lee EY, et al. Adenoma recurrence after piecemeal colonic EMR is predictable: the Sydney EMR recurrence tool. Gastrointest Endosc. 2017 Mar;85(3):647-656.e6.

9 Vinsard DG, Kandel P, Mejia Perez LK, Bingham RL, Lennon RJ, Woodward TA, et al. Adenoma recurrence after endoscopic mucosal resection: propensity score analysis of old and new colonoscopes and Sydney recurrence tool implementation. Endosc Int Open. 2018 Feb;6(2):E230-41.

10 Gupta S, Miskovic D, Bhandari P, Dolwani S, McKaig B, Pullan R, et al. A novel method for determining the difficulty of colonoscopic polypectomy. Frontline Gastroenterol. 2013 Oct;4(4):244-8

11 Longcroft-Wheaton G, Duku M, Mead R, Basford P, Bhandari P. Risk stratification system for evaluation of complex polyps can predict outcomes of endoscopic mucosal resection. Dis Colon Rectum. 2013 Aug;56(8):9606.
12 Hassan C, Antonelli G, Dumonceau JM, Regula J, Bretthauer M, Chaussade S, et al. Postpolypectomy colonoscopy surveillance: European Society of Gastrointestinal Endoscopy (ESGE) Guideline - Update 2020. Endoscopy. 2020 Aug;52(8):687-700.

13 Seo M, Song EM, Kim GU, Hwang SW, Park $\mathrm{SH}$, Yang DH, et al. Local recurrence and subsequent endoscopic treatment after endoscopic piecemeal mucosal resection with or without precutting in the colorectum. Intest Res. 2017 Oct;15(4):502-10.

14 Buchner AM, Guarner-Argente C, Ginsberg GG. Outcomes of EMR of defiant colorectal lesions directed to an endoscopy referral center. Gastrointest Endosc. 2012 Aug;76(2):25563.

15 Silva JC, Pinho R, Fernades C, Proença L, Rodrigues A, Silva AP, et al. Prediction of adenoma recurrence after piecemeal endoscopic mucosal resection: interobserver agreement and utilization of the Sydney EMR recurrence tool. Scand J Gastroenterol. 2020 Apr;55(4):492-6.

16 Alexandrino G, Figueiredo ML, Domingues TD, Lourenço LC, Carvalho R, Martins A. The risk of residual or recurring adenoma after piecemeal endoscopic mucosal resection of large non-pedunculated colorectal polyps is predictable. Eur J Gastroenterol Hepatol. 2020 Jun;32(6):713-7.

17 Desomer L, Tutticci N, Tate DJ, Williams SJ, McLeod D, Bourke MJ. A standardized imaging protocol is accurate in detecting recurrence after EMR. Gastrointest Endosc. 2017 Mar;85(3):518-26. 